\title{
¿VAMOS A HABLAR ANDALUZ O CANTAREMOS FLAMENCO?: LA EXPRESIÓN DEL FUTURO EN EL ESPAÑOL DE ANDALUCÍA
}

\author{
Kimberly Merckx \\ Universidad de Gante, Bélgica
}

\begin{abstract}
RESUMEN: Este trabajo es el resultado de un largo estudio morfosintáctico y semántico que no sólo está concebido como una síntesis de dos (sub)sistemas lingüísticos, el andaluz hablado y las coplas flamencas, sino que delimita además las formas de expresión futura cantaré y voy a cantar. A partir de una investigación contrastiva e inductiva propone un análisis de los factores que condicionan en cierta medida el uso de una u otra forma en ambos sistemas. La confrontación de los resultados aclara una posible reestructuración de las formas futuras en andaluz con base en la supuesta "decadencia" del futuro sintético a favor del analítico, tal como se observa también en la mayoría de las lenguas románicas.
\end{abstract}

ABSTRACT: This paper is the result of a detailed morphosyntactic and semantic study that is not only conceived as a synthesis of two linguistic (sub)systems spoken Andalusian and flamenco verses - but it also delineates the forms of future expression cantaré and voy a cantar. From a contrasting and inductive investigation it proposes an analysis of the factors that help to determine the use of one or other of the forms in both systems. In contrasting the results one can clarify a possible restructuring of the future forms in Andalusian based in the supposed "decadence" of the synthetic future in favour of the analytical future, similar to the current situation of the linguistic change observed in the majority of Roman languages.

PALABRAS CLAVE: español de Andalucía, futuro analítico $\leftrightarrow$ futuro sintético, valores temporales $\leftrightarrow$ valores modales

KEY WORDS: Spanish of Andalusia, analytical future $\leftrightarrow$ synthetic future, temporal values $\leftrightarrow$ modal values. 


\section{Introducción}

En los medios de comunicación tanto el andaluz como el flamenco han sido tratados con cierto desprecio. Sin embargo, como expresión de un grupo social específico -el gitano-andaluz ${ }^{1}$ - el flamenco representa una realidad importante de Andalucía y requiere por tanto un (re)conocimiento, no sólo como fenómeno cultural-antropológico sino también como categoría lingüístico-literaria ${ }^{2}:$ "[...] es una especie de "lengua funcional" en la que los signos, sobre todo léxicos, adquieren a veces aceptaciones particulares especializadas e incluso valores semánticos autónomos" (Ropero 2001: 455-456).

Hemos podido comprobar que la mayoría de los estudios sobre el andaluz y el flamenco están hechos en una perspectiva histórica, antropológica, musical, poética, etc. Las investigaciones desde la perspectiva lingüística y sincrónica en cambio escasean, en particular para los textos flamencos. En este terreno los estudios léxicos y semánticos les llevan gran ventaja. Falta por tanto un enfrentamiento profundo con temas morfosintácticos como el sistema verbal.

En los pocos estudios sobre la sintaxis andaluza se señala un proceso de avance del futuro analítico o perifrástico (FP) frente a un retroceso del futuro simple o sintético $(\mathrm{FS})^{3}$. Ante este hecho no faltan autores ${ }^{4}$ quienes se han atrevido a afirmar la inminente desaparición del FS en español.

En el presente artículo examinaremos la expresión de futuridad en andaluz hablado y en los cantes flamencos. Averiguaremos si estamos realmente ante una reestructuración del sistema verbal en andaluz.

1. La tradición flamenca comprende un mundo entero de modos de vida, de relaciones sociales y de experiencias históricas mezclando la cultura andaluza con la tradición gitana.

2. Al lado del baile, cante y toque, el arte flamenco se manifiesta también en el lenguaje, medio de expresión del sentimiento del pueblo andaluz. De acuerdo con la caracterización de Rodríguez Díez (1981:47), consideramos el lenguaje utilizado en los cantes como una lengua especial: "La lengua especial es la lengua de un grupo social en tanto que ésta difiere de la lengua común, no estando definido por criterios geográficos".

Este lenguaje gitano-andaluz nació de dos lenguas distintas, el romano-caló por un lado y el español-andaluz por otro lado, lo que le confiere al flamenco su personalidad lingüística. Sin embargo, por sus rasgos específicos determinados por factores extralingüísticos, el lenguaje flamenco se sitúa todavía en el margen de la lingüística y se incluye más fácilmente dentro de los estudios sociolingüísticos. A pesar de esta subvaloración, la importancia del lenguaje flamenco reside también en su aspecto gráfico: gracias al uso de una escritura diferenciada, se convierte en un soporte gráfico del andaluz hablado.

3. Infra.

4. Amado Alonso (1935: 81), Montes (1962: 529), Coseriu (1977: 15), Meier (1965: 77), etc. 
Para la finalidad que perseguimos en este artículo no podemos detenernos a precisar de manera detallada el concepto de tiempo futuro ni a exponer las distintas teorías que han intentado explicar las causas de la frecuente renovación de las formas ${ }^{5}$. Basta con señalar que este tiempo hace referencia a un proceso venidero que indica posterioridad con respecto a un punto de la sucesión temporal que coincide o no con el momento de la enunciación ${ }^{6}$. Aparte de esta definición tradicional, advertimos que la noción de futuridad encierra un doble valor, el propiamente temporal y el modal: "Si alguien nos pregunta qué hora es, podemos responder, son las cuatro o serán las cuatro, expresando son y serán un mismo tiempo, que es el momento en que proferimos la respuesta; pero son denotará certidumbre y serán cálculo, raciocinio, conjetura"(Bello 1988: 457, $\mathrm{n}^{\circ} 689$ ). Esta dualidad ${ }^{7}$ se refleja en casi todas las definiciones y referencias al tiempo futuro y nos ayuda, en cierta medida, a entender el porqué de su continua inestabilidad.

La investigación se hace contrastiva e inductiva: a partir de un corpus de textos orales y escritos, constituidos respectivamente por las encuestas del habla urbana de Sevilla, y por algunos cancioneros flamen $\cos ^{8}$, llegaremos a un sistema organizado de las formas futuras cuyo funcionamiento contrastaremos a continuación en los (sub)sistemas señalados. A partir de una investigación estadística proponemos un análisis de los factores sintácticos y semánticos que condicionan el uso del FS o del FP'. La confrontación de los datos de dichos (sub)sistemas nos ayudará a aclarar una posible reestructuración de las formas futuras en el sistema andaluz con base en la supuesta "decadencia" del FS en favor del FP. Finalmente,

5. Nos basamos principalmente en estudios como los de Berschin (1987), Gómez Manzano (1988), Montes (1962 y 1963), Moreno de Alba (1970), Sedano (1994).

6. Rojo (1988) relaciona la forma respectiva con el eje principal de referencia, el origen $(O)$ que Veiga define en Bosque y Demonte (1999: 2889) como "el centro deíctico de orientaciones temporales del sistema verbal, el punto desde el cual se enfoca, directa o indirectamente, todo proceso expresado por una forma verbal". De acuerdo con el sistema vectorial propuesto por Rojo, las formas estudiadas se representarán de la manera siguiente: $O+V$ y $(O o V)+V)$. Mientras que el FS expresa en ámbito primario posterioridad con respecto al origen, el FP indica posterioridad en el ámbito secundario, es decir, en relación con el punto central del ámbito primario.

7. Sirvan como muestra las palabras de Coseriu (1977: 29): "Lo que universalmente se comprueba es una duplicidad del futuro, que oscila entre dos polos: el que se suele indicar como puramente temporal y el modal".

8. Véase la bibliografía.

9. No pretendemos abarcar todos los factores que inciden en el empleo de cada una de las formas; sólo serán objeto de nuestro análisis los datos globales y algunos que hacen referencia a su distribución en contextos (extra)lingüísticos particulares. 
el análisis contrastivo con algunas investigaciones previas nos permitirá determinar la situación actual de las formas futuras en el andaluz y el flamenco ${ }^{10}$.

\section{El futuro en el flamenco y en el andaluz hablado: primera aproximación}

Desde la primera obra científica sobre el flamenco, se admite cierto paralelismo entre su lenguaje y el complejo sistema dialectal del andaluz ${ }^{11}$. Sin embargo, al considerar la distribución global de las formas futuras, se observa una diferencia significativa entre ambos códigos lingüísticos, como se nota en el cuadro 1.

\section{Cuadro 1}

\begin{tabular}{|l|l|c|c|c|}
\hline & \multicolumn{2}{|c|}{ Flamenco } & \multicolumn{2}{c|}{ Andaluz hablado } \\
\hline & $\begin{array}{c}\text { Forma en } \\
-\boldsymbol{r} e ́\end{array}$ & $\begin{array}{c}<\text { ir } \boldsymbol{a}+ \\
\text { infinitivo> }\end{array}$ & $\begin{array}{c}\text { Forma en } \\
-\boldsymbol{r e ́}\end{array}$ & $\begin{array}{c}<\text { ir } \boldsymbol{a}+ \\
\text { infinitivo> }\end{array}$ \\
\hline Valores temporales $^{12}$ & $478(84 \%)$ & $91(16 \%)$ & $57(23 \%)$ & $186(77 \%)$ \\
\hline Valores modales $^{13}$ & $297(89 \%)$ & $38(11 \%)$ & $148(46 \%)$ & $176(54 \%)$ \\
\hline TOTAL & $775(86 \%)$ & $129(14 \%)$ & $205(36 \%)$ & $362(64 \%)$ \\
\hline
\end{tabular}

10. Una dificultad que surge a menudo en las investigaciones contrastivas del tiempo futuro es el tratamiento de los matices aspectuales añadidos al de futuridad. A este respecto nos interesa señalar que <ir $a+$ infinitivo> expresa a veces un futuro inmediato o, desde otra perspectiva, un aspecto incoativo o ingresivo. En una parte dedicada a la distancia temporal expresada por ambas formas y a lo largo de un análisis semántico, intentamos especificar en qué punto de la escala temporal de futuridad se sitúa el proceso enunciado. En los datos globales en cambio, consideramos más conveniente incluir las formas aspectual-temporales en un solo grupo que hace referencia a lo venidero y que se opone a las formas en las que los valores modales predominan.

11. Dicho paralelismo se situará sobre todo en el nivel fonético.

12. Las formas temporales abarcan los casos en los que predomina la indicación de posterioridad. En general, las gramáticas consideran el valor temporal o futural como el "uso recto" del futuro (Rojo y Veiga, 1974: 68-149). Sin embargo, rechazamos la idea del futuro como categoría puramente temporal: por la naturaleza misma -abstracta y virtual- del tiempo futuro, se añaden casi siempre matices modales (la intención, la obligación, la amenaza, etc.).

13. Aun reconociendo la continuidad entre los valores temporales y modales, distinguimos las formas temporales de las en que predomina el valor modal. El punto de partido para determinar este valor modal siempre será la actitud del hablante con respecto a su enunciación. 
La divergencia porcentual del FS y el FP en andaluz y en flamenco es significativa y afecta tanto a los valores temporales como a los modales: la forma en -ré se asocia más al flamenco mientras que el andaluz hablado favorece el uso de la perífrasis. De acuerdo con Berschin ${ }^{14}$, los resultados anteriores nos permiten acercar los textos flamencos a la lengua escrita en que la forma en -ré representa un uso más culto y formal : "desde el punto de vista estilístico o diafásico, el futuro sintético predomina en la lengua escrita, elaborada, mientras que la lengua hablada y espontánea favorece el futuro analítico"(Berschin 1987:109).

A primera vista, el carácter escrito de los textos flamencos, que se deduce de la frecuencia elevada de la forma en -ré, implica cierta paradoja: a pesar de su fuerte tradición oral, las coplas se asocian tradicionalmente, como fenómeno cultural-literario del andaluz, a la lengua escrita. En este sentido, este género popular se acerca a otro tipo de literatura oral en Andalucía, el romancero, y se incluye dentro de la literatura de tradición oral. Aunque ésta no dista en esencia de los mecanismos formales de los demás textos literarios, se ajusta, eso sí a un modo de ser propio y diferencial.

Montes (1962: 538) incluso relaciona el uso frecuente de la forma en -ré en flamenco a "la voluntad estilística del cantor popular que busca dar a su creación una forma literaria, elevada."

El uso creciente de <ir $a+$ infinitivo > en la lengua hablada en cambio, coincide con una pérdida considerable de la importancia de la forma en -ré y una posible tendencia evolutiva propia del andaluz hablado. La investigación siguiente demuestra en qué medida existen factores, externos e internos, que condicionan el uso de una determinada forma.

\section{Análisis sintáctico y semántico del futuro}

Cuando nos enfrentamos a la diversidad de medios de que dispone la lengua para la expresión de posterioridad y modalidad hemos de plantearnos necesariamente la cuestión de si existe alguna razón de índole gramatical, sintáctica (§ 2.1.) o semántica, contextual (§ 2.2.) que condicione el uso o la preferencia por una u otra forma en determinado sistema lingüístico.

14. Véase también estudios previos como el de Sáez Godoy (1968). 


\subsection{Factores sintácticos}

\subsubsection{La estructura oracional}

A pesar de que no se observan notables restricciones de carácter sintáctico que favorezcan el empleo de una u otra forma, destacan en el corpus algunas tendencias a utilizar una determinada forma en cierto tipo de oración. Distinguimos entre el uso temporal (cuadro 2) y el uso modal (cuadro 3 ).

Cuadro 2: uso temporal

\begin{tabular}{|l|c|c|c|c|}
\hline & \multicolumn{2}{|c|}{ Flamenco } & \multicolumn{2}{c|}{ Andaluz hablado } \\
\hline & $\begin{array}{c}\text { Forma en } \\
-\boldsymbol{r e ́}\end{array}$ & $\begin{array}{c}<\text { ir } \boldsymbol{a}+ \\
\text { infinitivo> }\end{array}$ & $\begin{array}{c}\text { Forma en } \\
-\boldsymbol{r} \boldsymbol{e}\end{array}$ & $\begin{array}{c}<\text { ir } \boldsymbol{a}+ \\
\text { infinitivo }\end{array}$ \\
\hline 1. Independientes & $263(55 \%)$ & $45(49,5 \%)$ & $22(38,5 \%)$ & $97(52 \%)$ \\
\hline 2. Coordinadas & $76(16 \%)$ & $11(12 \%)$ & $13(23 \%)$ & $20(11 \%)$ \\
\hline 3. Subordinadas & $43(9 \%)$ & $35(38,5 \%)$ & $22(38,5 \%)$ & $69(37 \%)$ \\
\hline 4. Tras imperativo & $96(20 \%)$ & $/$ & $/$ & $/$ \\
\hline TOTAL & $478(100 \%)$ & $91(100 \%)$ & $57(100 \%)$ & $186(100 \%)$ \\
\hline
\end{tabular}

En primer lugar, ambas formas temporales se presentan principalmente, tanto en andaluz como en los textos flamencos, en las oraciones independientes. Sin embargo, en andaluz hablado, destaca la frecuencia elevada de <ir $a+$ infinitivo> que en las independientes incluso supera al FS.

Luego, las coordinadas parecen favorecer el uso del futuro en -ré mientras que las subordinadas presentan una distribución superpuesta: en flamenco, comprobamos un uso frecuente del FP; en andaluz hablado en cambio, el FS es más frecuente. Sin embargo, en las subordinadas del corpus hablado la divergencia entre ambas formas no es tan significativa (FS: 38,5\% vs FP: 37\%). Además, la distinción tradicional del flamenco -<completiva + FS > y <adverbial + FP >- se desvanece en la lengua hablada en que <ir $a+$ infinitivo > extiende cada vez más su territorio: 
(1) Porque yo llevo... yo tengo ya cincuenta y cuatro años y desde que nací estoy escuchando diciendo que va a cambiar... que va a cambiar, y que va a cambiar y nunca cambia, y tengo ya cincuenta y cuatro años escuchando lo mismo. (P3V: 452) ${ }^{15}$

(2) [...] Que además yo estoy muy disgustada porque se marcha, se va a marchar ahora. (P3H: 477)

De los datos anteriores se deduce una vez más que en la lengua hablada, la importancia del FP con valor temporal es cada vez mayor. En este sentido, podríamos estar ante una reestructuración de los contextos sintácticos en los que el FP entra en fuerte competencia con el FS. A esto se debe añadir que contrariamente a su variante sintética, la perífrasis presenta menos restricciones: indiferente a la dependencia sintáctica, se utiliza en las subordinaciones temporales y en la prótasis de oraciones condicionales.

(3) Blanco fue mi nacimiento.

Verde mi mediana edad,

Y luego me vuelvo negra

Cuando me van a matar.

—La mora. (Cantos populares españoles, $n^{\circ} 559$ )

(4) Pues yo opino que o una de dos; o las dejan o no las dejan; ahora, si las van a autorizar a salir, eso es un lío, porque nosotros tuvimos que tomar la determinación... (P2V: 293)

\section{Cuadro 3: uso modal}

\begin{tabular}{|l|c|c|c|c|}
\hline & \multicolumn{2}{|c|}{ Flamenco } & \multicolumn{2}{c|}{ Andaluz hablado } \\
\hline & $\begin{array}{c}\text { Forma en } \\
-r e ́\end{array}$ & $\begin{array}{c}<\text { ir } \boldsymbol{a}+ \\
\text { infinitivo> }\end{array}$ & $\begin{array}{c}\text { Forma en } \\
-r e ́\end{array}$ & $\begin{array}{c}\text { <ir } \boldsymbol{a}+ \\
\text { infinitivo> }\end{array}$ \\
\hline 1. Independientes & $193(65 \%)$ & $33(87 \%)$ & $68(46 \%)$ & $114(65 \%)$ \\
\hline 2. Coordinadas & $27(9 \%)$ & $2(5 \%)$ & $27(18 \%)$ & $18(10 \%)$ \\
\hline 3. Subordinadas & $33(11 \%)$ & $2(5 \%)$ & $53(36 \%)$ & $44(25 \%)$ \\
\hline 4. Tras imperativo & $44(15 \%)$ & $1(3 \%)$ & $/$ & $/$ \\
\hline TOTAL & $297(100 \%)$ & $38(100 \%)$ & $148(100 \%)$ & $176(100 \%)$ \\
\hline
\end{tabular}

15. Las cifras que aparecen al final de cada ejemplo sacado de las Encuestas se leen de la manera siguiente: la primera letra indica el nivel sociocultural $(\mathrm{C}=$ culto; $\mathrm{P}=$ popular); el número que sigue indica el grupo generacional (1=hasta los 30 años, 2=30-50 años, $3=$ más de 50 años); la segunda letra refiere al sexo (V=varón, hombre; $\mathrm{H}=$ hembra, mujer); los siguientes números son las páginas donde se puede leer la encuesta completa. 
A primera vista, el comportamiento sintáctico de las formas modales presenta menos diferencias que en el caso de las temporales. Sin embargo, a pesar de una presión considerable de <ir $a+$ infinitivo > en la oración independiente (tanto en flamenco como en andaluz), la forma en -ré resiste aparentemente más a la fuerte competencia de la perífrasis. Prevalece por ejemplo en la mayoría de los contextos sintácticos (las coordinadas, las subordinadas y tras imperativo), incluso en andaluz hablado.

(5) Para un turista supongo que lo que le gustará más será el flamenco. (C2H: 157)

(6) No sé si eso se podrá decir aquí, pero, desgraciadamente, es verdad. (C3H: 253)

\subsubsection{Los indicadores temporales y modales}

El segundo factor contextual al que prestamos atención es la combinación de la forma en -ré o <ir $a+$ infinitivo> con determinaciones temporales o modales. Estos indicadores contextuales determinan en gran parte el valor de las formas verbales y contribuyen además a detectar las posibilidades de alternancia.

En el caso de los valores temporales, intentamos precisar el grado de distancia temporal expresada por cada forma en función del indicador temporal: la inmediatez, la proximidad ${ }^{16}$ y el alejamiento:

\section{Cuadro 4: uso temporal}

\begin{tabular}{|l|c|c|c|c|}
\hline & \multicolumn{2}{|c|}{ Flamenco } & \multicolumn{2}{c|}{ Andaluz hablado } \\
\hline & $\begin{array}{c}\text { Forma en } \\
-\boldsymbol{r} \boldsymbol{e}\end{array}$ & $\begin{array}{c}<\text { ir } \boldsymbol{a}+ \\
\text { infinitivo }\end{array}$ & $\begin{array}{c}\text { Forma en } \\
-\boldsymbol{r} \boldsymbol{e}\end{array}$ & $\begin{array}{c}<\text { ir } \boldsymbol{a}+ \\
\text { infinitivo> }\end{array}$ \\
\hline Inmediatez & $1(1 \%)$ & $11(42 \%)$ & $0(0 \%)$ & $27(43 \%)$ \\
\hline Proximidad & $34(33 \%)$ & $9(35 \%)$ & $6(28,5 \%)$ & $25(40 \%)$ \\
\hline Alejamiento & $69(66 \%)$ & $6(23 \%)$ & $15(71,5 \%)$ & $11(17 \%)$ \\
\hline TOTAL & $104(100 \%)$ & $26(100 \%)$ & $21(100 \%)$ & $53(100 \%)$ \\
\hline
\end{tabular}

16. La proximidad difiere de la inmediatez por su mayor grado de distancia temporal: a pesar de que no designa una acción inmediatamente posterior al acto de hablar, las acciones se sitúan todavía en el mismo día, mes, año, etc. del momento de enunciación (hoy, a las cinco, esta tarde, este año, etc.). 
A primera vista, el FP presenta un mayor porcentaje de uso con las expresiones que implican una menor distancia temporal, mientras que con los adverbios de alejamiento, se emplea más el FS. El factor decisivo que justifica estos resultados es la relación entre el grado de distancia y la ruptura o continuidad de la forma verbal con respecto al origen. En este sentido, el FS es significativamente más frecuente para indicar la posterioridad lejana puesto que supone una ruptura con el momento de la enunciación: el grado de distancia temporal con respecto al presente es grande y va hacia el máximo en el futuro indeterminado del tipo alguna vez, siempre, etc. $\langle$ Ir $a+$ infinitivo > en cambio, indica coexistencia con el origen. Suele combinarse con adverbios de temporalidad inmediata o próxima, ocasionalmente con valor de alejamiento. Se explica por la presencia del vector de simultaneidad con el origen: el FP se relaciona más fácilmente con adverbios que incluyen también este origen, como $y a^{17}$ y ahora. Además, la morfología del presente confirma esta mayor relación con el origen.

Sin embargo, contrariamente a lo que se ha señalado en estudios anteriores, los datos ponen de manifiesto que <ir $a+$ infinitivo> no se limita exclusivamente a expresar un futuro inmediato: se combina con una gran diversidad de adverbios, tanto indicando la distancia temporal mínima como la posterioridad más lejana o imprecisa. Así pues, a pesar de que el FS y el FP expresan la posterioridad con formas de contenido diferentes, un factor contextual puede neutralizar la diferencia de enfoque temporal en flamenco y en andaluz y las formas, en combinación con algún indicador temporal, pueden recubrir un ámbito temporal idéntico. Este fenómeno anuncia posiblemente una reestructuración de los valores temporales, en particular el uso de la perífrasis con expresiones que indican un porvenir lejano, impreciso o muy amplio (dentro de x años, algún día, siempre, etc.), o sea una distancia temporal máxima. Gracias a esta posibilidad de expresar cada grado de distancia temporal, el uso de <ir $a+$ infinitivo> progresa efectivamente en detrimento del futuro en -ré.

Para los valores modales, se constata una tendencia similar, es decir, una progresiva extensión de la perífrasis que, en combinación con algún indicador modal (verbo, adverbio, conjunción, entonación, etc.), llega a adoptar valores modales similares a los de la forma en -ré: la (im)posibilidad, (in)seguridad, etc. de la pro-

17. Señalamos también la especialización del adverbio ya: al combinarse con el FP expresa una prontitud que no adopta con el FS. Ya refuerza la proximidad del proceso denotado por el FP y se pueden añadir algunos matices intencionales: Ya yo te voy a dejar, porque no tengo que darte; (...) (Cantos populares españoles, $n^{\circ}$ 4103). 
posición. Sin embargo, estos valores epistémicos se limitan por el momento al uso de <ir $a+$ infinitivo > en la lengua hablada y en combinación con alguna marca modal con valor epistémico.

(7) Hombre, es que no sé si voy a ir... porque depende de... de lo que tengamos que hacer o... si salimos... o que no (...) (P2V: 227)

Aparte de eso, la forma sintética goza de buena salud en el campo de la modalidad, incluso en la lengua hablada, en particular su valor de probabilidad ${ }^{18}$ que le garantiza un uso productivo en el paradigma verbal. Estos usos modales son además mucho más frecuentes de lo que prescriben las gramáticas.

(8) Probablemente, [...] será un hombre que vivirá, desde un punto de vista económico, desahogadamente. (C2V: 141)

(9) Ahora estarán saliendo ya los carteles de Semana Santa, ¿no? (P1V3: 84)

\subsubsection{La persona gramatical}

El tercer factor analizado en el uso del futuro es el de la persona gramatical: en la fase actual, la forma en -ré se relaciona principalmente con la tercera persona (anafórica, la que no participa activamente en el acto de habla) e <ir $a+$ infinitivo> con la primera persona (deíctica). Estas tendencias son notables en la lengua hablada pero, además, se confirman en flamenco.

En una fase siguiente, se prevé posiblemente una extensión del uso de la perífrasis temporal a la tercera persona ${ }^{19}$. Por el momento, esta tendencia sólo se produce en andaluz hablado en que, desde un punto de vista general, todavía predomina la primera persona. Esta hipótesis se justifica por el deseo manifiesto de concretar los procesos futuros: en un primer tiempo, el hablante, mediante la forma analítica, trae al presente la categoría abstracta del futuro. Luego, extiende esta tendencia a las personas que no forman parte del discurso.

18. En vez de expresar el valor temporal de posterioridad $O+V$, el futuro de probabilidad indica una relación de simultaneidad al origen $O \not \emptyset$, p.e. -¿Qué hora es? -Serán las diez.

19. A diferencia de las personas del discurso, la tercera persona es más abstracta, lejana y a veces desconocida porque no participa en la conversación. Correlativamente, el FS se caracteriza por su carácter indeterminado y abstracto. La perífrasis en cambio, prefiere lo concreto, lo que está presente en la situación comunicativa: el hablante recurre espontáneamente al FP para hablar de sí mismo o del interlocutor. 
A pesar del uso frecuente de los valores intencionale ${ }^{20}$ en primera persona, los datos de las formas modales van en el mismo sentido que los de las temporales: la extensión del uso de la perífrasis a todas las personas gramaticales. Al deseo de manifestar una continuidad con el presente se añadirá por tanto la voluntad de precisar los valores modales mediante la perífrasis. Sin embargo, por el momento, la forma en -ré, en particular en la lengua hablada, todavía predomina para expresar la modalidad. Por consiguiente, su sustitución por la forma analítica ocurrirá primeramente en las formas temporales.

\subsection{Factores semánticos}

\subsubsection{Valores temporales}

En líneas anteriores ya hicimos referencia a la distribución opuesta del FS y FP en ambos tipos de corpus. A pesar de esta discrepancia porcentual, el uso de las formas temporales es bastante similar en flamenco y en andaluz hablado: el FS indica prototípicamente la distancia temporal lejana o indeterminada sin establecer conexión con el presente mientras que la perífrasis expresa, al lado de la proximidad y la inmediatez ([+ conexión] $)$, también el alejamiento ${ }^{21}$.

Estos valores temporales se manifiestan claramente en las secuencias de futuridad porque si, en un mismo contexto, varias formas de futuro se siguen, el orden normal es primero la perífrasis y después el FS. Se debe sin duda a las características inherentes a ambas formas con respecto a la distancia temporal: la acción a la que se refiere el futuro es posterior a la referida por la perífrasis.

(10) Canto ésta y no más canto,

Porque voy a dormir;

Que mañana, si Dios quiere,

Nadie velará por mí. (Cantos populares españoles, n³313)

(11) Como Miguel no puede estar allí y lo voy a arrendar para julio, para agosto, y entonces, pues luego en septiembre coge Miguel otros veinte días, y entonces me iré a la playa, porque éste se quiere ir por ahí este año, se quiere ir por ahí otra vez este año; (P2H2: 325)

20. La modalidad intencional normalmente sólo se da en primera persona.

21. Sin embargo, recordamos que, en combinación con alguna determinación temporal, los valores temporales "prototípicos" se neutralizan y ambas formas pueden alternarse. 
Además, algunas secuencias estudiadas parecen confirmar la tendencia de sustituir el FS por el analítico, por lo menos en la lengua hablada. Efectivamente, el orden inverso, en que el FS precede y la perífrasis refiere a un punto posterior de la escala temporal, es muy frecuente en andaluz hablado:

(12) [...] el día de mañana se tendrán que casar, y cuando se casen no van a ser... seguir igual, sino que cada uno va a coger su línea y... Sí, se verán, se tomarán algunas copas, se... eso, pero que no se van a ver todos los días ni nada, como ahora... (P2V1: 212)

Dichas secuencias son tanto más interesantes cuanto aparentemente se oponen a la explicación tradicional, conforme a los valores temporales de ambos futuros. En realidad, en vez de constituir de usos excepcionales, los casos ilustran más bien la extensión de la perífrasis que, en los contextos anteriores, suplanta al FS. Al mismo tiempo, mediante el FP, el hablante añade al enunciado un matiz de determinación y seguridad mucho más destacado.

\subsubsection{Valores modales}

En la introducción hacíamos referencia a la dualidad de valores que encierra la noción de futuridad; no nos sorprende, pues, que la forma en -ré y la perífrasis pierdan a veces su significado temporal y pasen a expresar otros valores.

En el campo de la modalidad, se distinguen esencialmente entre la modalidad epistémica $^{22}$, asociada a la forma en -ré y la modalidad intencional, relacionada con la perífrasis. Aparte de las dos categorías básicas, nuestra investigación trata algunos valores modales más, entre ellos la modalidad deóntica. En conjunto, se obtiene la distribución siguiente:

22. Según Bauhr (1989: 77-80), la modalidad epistémica tiene que ver con el "valor veritativo de las proposiciones". Existen distintas posibilidades como lo (im)posible, (im)probable, (in)seguro que se traducen en actitudes del hablante. 
Cuadro 5

\begin{tabular}{|l|c|c|c|c|}
\hline & \multicolumn{2}{|c|}{ Flamenco } & \multicolumn{2}{c|}{ Andaluz hablado } \\
\hline & $\begin{array}{c}\text { Forma en } \\
-\boldsymbol{r e ́}\end{array}$ & $\begin{array}{c}<\text { ir } \boldsymbol{a}+ \\
\text { infinitivo> }\end{array}$ & $\begin{array}{c}\text { Forma en } \\
-\boldsymbol{r e ́}\end{array}$ & $\begin{array}{c}<\text { ir } \boldsymbol{a}+ \\
\text { infinitivo }\end{array}$ \\
\hline $\begin{array}{l}\text { Probabilidad } \\
\text { o inseguridad }\end{array}$ & $187(63 \%)$ & $/$ & $129(87 \%)$ & $55(31 \%)$ \\
\hline Intención & $71(24 \%)$ & $17(45 \%)$ & $6(4 \%)$ & $30(17 \%)$ \\
\hline Necesidad & $30(10 \%)$ & $8(21 \%)$ & $3(2 \%)$ & $42(24 \%)$ \\
\hline Otros & $9(3 \%)$ & $13(34 \%)$ & $10(7 \%)$ & $49(28 \%)$ \\
\hline TOTAL & $297(100 \%)$ & $38(100 \%)$ & $148(100 \%)$ & $176(100 \%)$ \\
\hline
\end{tabular}

La forma en -ré expresa prototípicamente la modalidad epistémica, en particular la probabilidad o incertidumbre. Esta tendencia es aún más notable en la lengua hablada en que las modalidades deóntica e intencional apenas constituyen el 6\% de los ejemplos estudiados. La distribución de los valores modales de <ir $a+$ infinitivo > difiere significativamente en ambos tipos de corpus: en flamenco, la perífrasis expresa en casi la mitad de los casos la modalidad intencional. De la modalidad epistémica en cambio, no hemos encontrado ningún ejemplo. En andaluz hablado, la perífrasis ya no se limita a la modalidad intencional. Expresa los mismos valores modales, incluso epistémicos, que la forma en -ré.

A primera vista, la forma en -ré e <ir $a+$ infinitivo> comparten varios valores semánticos para indicar alguna modalidad. Se propone por lo tanto un estudio más detallado para averiguar la posibilidad de una variación completamente libre entre las formas.

\section{1) Modalidad epistémica}

A pesar de que la futuridad siempre implica, al lado de la posterioridad, una eventualidad de la acción, se observa un comportamiento diferente para la forma en -ré e <ir $a+$ infinitivo> en la expresión de este valor modal.

Si el futuro en -ré indica un proceso venidero, casi siempre acusa una eventualidad implícita. Sin embargo, al intensificar la marca de eventualidad, la futu- 
ridad pasa a veces al segundo plano o incluso se anula: la probabilidad, la sorpresa, etc. por ejemplo trasladan su significación hacia el presente:

(13) Me gusta mucho Sevilla... seré, no sé, muy localista, no sé, la encuentro una ciudad, pues...(C2H: 166)

(14) No serás tú el primer hombre

ni yo la primera mujer

que se quieran y se olviden

y se vuelvan a querer. (Cantes flamencos y cantares, p. 285)

Al lado de la modalidad en el presente, la forma en -ré expresa también la probabilidad o eventualidad en el futuro: muchas veces, se debe explicitar ese carácter mediante algún indicador modal.

La perífrasis se limita a este último uso modal: en combinación con alguna marca formal, indica una modalidad en el futuro. De ahí que el matiz temporal nunca llegue a anularse por completo y que los valores modales no trasladen su significación hacia el presente. Además, para expresar este tipo de modalidad epistémica, <ir $a+$ infinitivo> siempre debe combinarse con indicadores explícitos.

A pesar de estas restricciones de la perífrasis, en ciertos contextos, ambas formas sí parecen decir lo mismo:

(15) En esta cama m' acuesto;

No sé si amaneceré,

Con Dios confieso y comulgo

$\mathrm{Y}$ espero en su santa fe. (Cantos populares españoles, $\mathrm{n}^{\circ}$ 1042)

(16) No, es que no me gusta, es que no sé si voy a ir porque no sé... (P2V: 227)

Sin embargo, en los ejemplos anteriores surgen algunas diferencias pragmáticas, debidas al control de los hablantes sobre el acontecimiento futuro. Cuando el hablante domina por sí mismo el desenlace futuro, el grado de seguridad aumenta y se utiliza preferentemente la perífrasis. $\mathrm{Al}$ recurrir a la forma en -ré en cambio, disminuye considerablemente la certidumbre del hablante porque el resultado final no está en sus propias manos ${ }^{23}$.

23. En el ejemplo (15), el proceso futuro de amanecer depende enteramente de la voluntad de Dios, o sea, de una tercera persona, lo que refuerza aún más la inseguridad del hablante. 
En este sentido, para indicar la eventualidad en el futuro se suele utilizar más frecuentemente la forma en -ré: el hablante, al referirse a procesos más alejados de la realidad y menos realizables, adoptará un distanciamiento en relación con sus aseveraciones ${ }^{24}$.

\section{2) Modalidad deóntica}

En nuestro corpus, la necesidad u obligación se expresa tanto por la perífrasis como por el FS. Sin embargo, surge una diferencia importante al nivel de la fuerza imperativa: <ir $a+$ infinitivo> refuerza aún más el valor imperativo de la orden ${ }^{25}$ :

(19) Dueño mío, si te vieres

En la presencia de Dios,

Le pedirás que me muera,

Que sin ti no vivo yo. (Cantos populares españoles, $n^{\circ} 2629$ )

(20) Ahora me vas a contar algo de la Feria. (C3H: 293)

Según el grado de fuerza imperativa, la perífrasis precede por tanto en la jerarquía a la forma en -ré. Esta jerarquía corresponde también a una mayor seguridad en la realización de la orden.

Igual que la forma en -ré, la condición previa para utilizar <ir a + infinitivo> con valor imperativo reside en que la orden será obedecida sin falta. Sin embargo, difiere el grado de seguridad expresada por cada forma: al utilizar <ir a + infinitivo>, destaca la seguridad del hablante de una pronta contestación del

24. Los ejemplos siguientes confirman la idea de que, en el caso de la perífrasis, el hablante controla mucho más la acción denotada por el verbo que con la forma en -ré:

(17) [...] yo mismo desconozco si me voy a quedar en los nueve o diez libros de poesía que creo que tengo, o van a llegar a cincuenta, o no van a mantener un nivel de calidad, o superándome o pasar de ahí, en fin, o si voy a tirar por otro género, si mi obra va a ser muy extensa, y no solamente ya extensa, que sería lo de menos, sino si, en la extensión, la voy a mantener en un nivel de calidad, o superándome o manteniéndome, o hasta podría descender. $(\mathrm{C} 2 \mathrm{H}: 182)$

(18) Tengo un dolor no sé dónde,

Nacido de no sé qué;

Sanaré yo no sé cuándo,

Si me cura no sé quién. (Cantos populares españoles, $n^{\circ} 1671$ )

25. Wilmet (1997: 382) confirma esta mayor fuerza de mando con la perífrasis al pretender que " $T u$ vas faire accroît le caractère impérieux de tu feras: le locuteur prétend percevoir les signes actuels d'un avenir justifiant son pronostic." 
interlocutor. Además, el resultado del mandato se presenta como el desarrollo natural de la situación ya existente en el momento de origen. Con la forma en -ré en cambio, se produce una ruptura entre el cumplimiento posterior del mandato y el acto de habla. Así, en el ejemplo citado, la ruptura se manifiesta por la inserción de Si te vieres en la presencia de Dios.

En este sentido, tanto el grado de seguridad como la conexión con el origen están íntimamente relacionados con la manera de enfocar la realización futura de la orden.

\section{3) Modalidad intencional}

A pesar de que la modalidad intencional se relaciona más frecuentemente con la perífrasis, ambas formas muestran en nuestro corpus una contigüidad funcional en la expresión de la promesa. Veyrat Rigat (1993:93-94) nos da una posible explicación de la alternancia entre el FS y la perífrasis: se confunden los valores temporales de la forma en -ré con el valor modal de <ir $a+$ infinitivo>:

\footnotetext{
"La razón de la confusión al considerar esta construcción como equivalente al futuro es la estrecha relación que existe en la conciencia del hablante entre la intencionalidad y la prospectividad. Cualquier acción que se sitúe en la zona de nuestras intenciones, deberá realizarse temporalmente en la época futura. Pero una intención no tiene naturaleza temporal, sino que su carácter es subjetivo, y en ella se ve involucrada la participación del sujeto. [...] ambos valores pueden coaparecer y mostrar sincretismo cuando ni la temporalidad ni la modalidad están marcadas en la oración por los elementos correspondientes".
}

Examinemos un ejemplo del corpus flamenco:

(21) Yo te querré en este mundo y te adoraré en el otro.

Al sustituir las formas sintéticas por yo te voy a querer... y te voy a adorar, se produce un cambio en el grado de firmeza. En el caso del FS se trata de una promesa categórica: "Creemos que convendría destacar que la nota dominante de la forma iré frente a voy a ir, voy, es la enfática, la de promesa categórica”" (Lorenzo 1980:109).

Otra divergencia entre las formas se explica por el grado de presión ejercida por el interlocutor. Al utilizar la forma en -ré, el hablante parece adaptarse más a los deseos del interlocutor y, cediendo ante su voluntad, opta por la actitud más conveniente en la situación en que se encuentra :

(22) No me pegue osté;

Por los ojitos que tengo en la cara

Yo m’enmendaré. (Cantes flamencos, recogidos y anotados...n ${ }^{\circ} 118$ ) 
Con <ir $a+$ infinitivo> en cambio, el hablante controla mucho más sus propias decisiones. De ahí que en estos contextos la promesa expresada por la perífrasis pase a menudo como más sincera.

(23) Ellos no me veían igual, excepto un par de ellos o tres que insistían por invitarme, que para acá, que para allá, ven para acá... al final mi mujer... hacía frío, mi mujer no estaba demasiado a gusto y "vámonos, vámonos” y a las diez de la noche estaba aquí. De todas maneras voy a... voy a seguir con la experiencia, me... los martes, seguramente en verano cuando haga calor voy a principio, ya me aceptarán, no sé, son gente que... a mí me gus... yo estando trabajando las de tratarlos como clientes me... quiero tratarlos como ya ... (P1V: 54)

En fin, constatamos que la alternancia de ambas formas es más difícil en los contextos en que el grado de modalidad es más fuerte. Incluso, en los casos en que el matiz temporal de futuridad se anula por completo (futuro de probabilidad), la variación es imposible. Con la modalidad deóntica y la eventualidad futura en cambio, la forma en -ré e <ir $a+$ infinitivo> son más fácilmente permutables a pesar de algunos ligeros cambios en la manera de enfocar los procesos.

En resumen, los datos semántico ${ }^{26}$-sintácticos destacan el número creciente de la perífrasis, sobre todo en andaluz hablado. Por tanto, cabe cuestionar seriamente la existencia o sobrevivencia del FS en andaluz, por lo que la forma en -ré, frente a <ir $a+$ infinitivo> parece a veces más bien una imposición alomórfica normativa.

26. Al lado de los valores temporales y modales, existe un tercer tipo de valores semánticos: los expresivos, o sea, un subgrupo de formas en -ré e <ir a + infinitivo> que no forman parte de los usos temporales o modales de las formas respectivas. Se dan principalmente en la lengua hablada en que actúan como conectores supraoracionales: su funcionamiento se limita esencialmente a indicar ciertos valores discursivos.

(24) Pues verás... mi padre nació aquí en Sevilla. (C1H: 80)

(25) Me parece que tenía yo... vamos a ver... yo nací el veintinueve, tenía yo treinta y un años. (C2V: 110)

(26) Pues mira, de la Semana Santa de Sevilla, qué te voy a decir, que es lo más grande del mundo entero; ni Feria ni nada, la Feria queda en segundo puesto. (P2H: 347) 


\section{3. ¿Estamos ante une reestructuración del sistema verbal con una progresiva desaparición de la forma en -ré?}

Un problema a menudo citado acerca de la competencia entre el FS y el FP es el de la "decadencia", o incluso de la desaparición del FS en favor del presente de indicativo y de la perífrasis $\left\langle\right.$ ir $a+$ infinitivo ${ }^{27}$. A este respecto nos parece oportuno recordar que Sáez Godoy (1968: 1875-1890), en su estudio sobre la evolución de las formas que expresan futuro, examinó textos escritos desde Cervantes hasta autores dramáticos del siglo XX, y observó que el presente y sobre todo la perífrasis iban ganando terreno poco a poco a la forma en -ré.

Cuadro 6

\begin{tabular}{|l|c|c|c|c|c|}
\hline & Cervantes & $\begin{array}{c}\text { Lope } \\
\text { De Vega }\end{array}$ & Bretón & $\begin{array}{c}\text { García } \\
\text { Lorca }\end{array}$ & $\begin{array}{c}\text { Autores } \\
\text { modernos }\end{array}$ \\
\hline Futuro sintético & $81 \%$ & $79 \%$ & $82 \%$ & $78 \%$ & $62 \%$ \\
\hline Haber de + infinitivo & $17 \%$ & $18 \%$ & $12 \%$ & $3 \%$ & $1 \%$ \\
\hline Presente futúrico & - & - & $0,3 \%$ & $2 \%$ & $4 \%$ \\
\hline Ir a + infinitivo & - & $2 \%$ & $6 \%$ & $15 \%$ & $33 \%$ \\
\hline Futuro semisintético & $1 \%$ & - & - & - & - \\
\hline
\end{tabular}

Si nos fijamos ahora en los datos anteriormente expuestos y los comparamos con los que aduce el autor, observamos que este proceso de avance de la primera y de retroceso de la última es más lento en flamenco que en andaluz hablado. Efectivamente, las circunstancias sintácticas, semánticas e incluso sociolingüísticas ${ }^{28}$ de la lengua hablada parecen irse confabulando para determinar la supuesta decadencia del FS. Su frecuencia baja se debe esencialmente a la fuerte competencia del FP que, en el caso concreto de <ir $a+$ infinitivo>, se traduce sobre todo en que las tres expresiones de futuro (inmediato, próximo y lejano) se realizan a través de la perífrasis. A esto se añade la extensión de <ir $a+$ infinitivo> en los distintos contextos

27. Supra

28. Infra 
sintácticos (en las independientes, con indicadores de alejamiento y en las personas del discurso) y en el campo de la modalidad, en particular en la lengua hablada.

Sin embargo, por muy avanzado que esté el fenómeno de la perífrasis, la forma en -ré está menos en decadencia de lo que a menudo se piensa. Así, no es difícil comprobar que, muchas veces, la forma sintética sigue expresando futuro, y tanto más en el flamenco ( lengua escrita). Al lado de sus valores temporales mantiene además una productividad considerable en el campo de la modalidad, incluso en la lengua hablada. Nuestro análisis sociolingüístico ${ }^{29}$ confirma los datos obtenidos: la aceptación del FS entre los sevillanos cultos es óptima e, incluso, supera la de la forma perifrástica. Nos parece, por tanto, arriesgado pronosticar una desaparición absoluta e inminente de la forma en -ré.

\section{4. ¿Cómo interpretar los datos con respecto a investigaciones previas, en particular con respecto al español peninsular?}

Varios estudios sobre la expresión de futuridad han puesto de manifiesto que en casi todo el ámbito hispánico, <ir $a+$ infinitivo> es el medio más habitual para expresar el futuro. Asimismo, en nuestra investigación sobre el flamenco y el andaluz hablado, en particular el habla urbana de Sevilla, hemos tenido ocasión de comprobar que dicha forma alterna cada vez más con la forma en -ré, tanto en la expresión de la posterioridad como de la eventualidad de una acción.

\section{Cuadro 7}

\begin{tabular}{|l|c|c|c|c|}
\hline & \multicolumn{2}{|c|}{ Valores temporales } & \multicolumn{2}{c|}{ Valores modales } \\
\hline & $\begin{array}{c}\text { Forma en } \\
-r e ́\end{array}$ & $\begin{array}{c}\text { <ir } \boldsymbol{a}+ \\
\text { infinitivo> }\end{array}$ & $\begin{array}{c}\text { Forma en } \\
-r e ́\end{array}$ & $\begin{array}{c}\text { <ir } \boldsymbol{a}+ \\
\text { infinitivo> }\end{array}$ \\
\hline Nivel sociocultural & Culto & Popular & Popular & Popular \\
\hline Edad & $3^{\text {a generación }}$ & $1^{\text {a generación }}$ & $2^{\text {a generación }}$ & $2^{\text {a generación }}$ \\
\hline Sexo & Mujer & Hombre & Mujer & Hombre \\
\hline
\end{tabular}

29. Infra 
En este sentido, la sustitución de la forma en -ré por <ir $a+$ infinitivo> no es un fenómeno exclusivo de esta área lingüística. Se producen tendencias semejantes en canario, en el español peninsular y de América ${ }^{30}$. Además, el deseo de actualizar los acontecimientos venideros mediante la perífrasis no se limita al español actual. Basta con recordar el origen de los futuros romances, derivados de una forma del presente o la formación del futuro en las lenguas germánicas, siempre a partir de una forma flexionada del presente.

Sin embargo, para interpretar nuestros resultados con más precisión, hemos completado el estudio lingüístico por un enfoque sociolingüístico. A este respecto examinamos la incidencia o divergencia respectiva de tres variables sociolingüísticas en el corpus hablado: el nivel sociocultural, la edad y el sexo.

En el campo de la temporalidad, se percibe una correlación de frecuencia entre las formas estudiadas de futuridad y los factores externos como la educación, la edad y el sexo, de modo que los menos escolarizados, los más jóvenes, y los hombres son los grupos más activos en promover el uso "no-estándar" del futuro analítico. Correlativamente, el segundo hecho relacionado con las variables extralingüísticas es el porcentaje considerablemente superior del FS entre las personas más cultas, la generación de más avanzada edad y las mujeres.

Al comparar los datos del flamenco con las variables señaladas destaca que el lenguaje de las coplas se asemeja considerablemente más a los usos lingüísticos del andaluz culto: para expresar la futuridad o eventualidad de una acción futura se recurre esencialmente a la forma en -ré. En este sentido, el flamenco se acerca otra vez más al registro escrito, tradicionalmente asociado al lenguaje de los cultos. Debido a este carácter escrito, el flamenco no corresponde en absoluto a los resultados de la lengua hablada.

30. El cuadro siguiente recoge, al lado de nuestros resultados, los resultados de algunas investigaciones previas realizadas en otras ciudades de habla hispana:

Cuadro 8

\begin{tabular}{|l|c|c|l|c|c|}
\hline & Forma en $-\boldsymbol{r e ́}$ & $\langle i \boldsymbol{a}+\mathbf{i n f i n i t i v o}\rangle$ & & Forma en $-\boldsymbol{r} \boldsymbol{e}$ & $\langle$ ir $\boldsymbol{a}+$ infinitivo> \\
\hline Rep. Dominicana & $2 \%$ & $98 \%$ & México (culto) & $31,2 \%$ & $68,8 \%$ \\
\hline Chile & $3,6 \%$ & $96,4 \%$ & Las Palmas (culto) & $38,1 \%$ & $61,9 \%$ \\
\hline Rosario & $20 \%$ & $80 \%$ & Madrid (culto) & $42,9 \%$ & $57,1 \%$ \\
\hline Puerto Rico & $21,8 \%$ & $78,2 \%$ & Flamenco & $84 \%$ & $16 \%$ \\
\hline Caracas & $23 \%$ & $77 \%$ & Sevilla & $23 \%$ & $77 \%$ \\
\hline
\end{tabular}

Véase: Berschin (1987), Gómez Manzano (1988), Montes (1962 y 1963), Moreno de Alba (1970), Sedano (1994), Troya Déniz (1998). 
En fin, deducimos del estudio sociolingüístico que las tendencias constatadas en el habla de Sevilla no coinciden completamente con las de otras ciudades de habla hispana. Se debe esencialmente al hecho de que el andaluz, a diferencia de las demás hablas, se caracteriza, tanto en el nivel culto como en su expresión escrita -el flamenco- por un uso más arraigado del FS. Además, el uso modal de la forma en -ré es mucho más notable en andaluz que en las demás áreas linguísticas. Por tanto, si admitimos alguna evolución en la sustitución de la forma sintética por la analítica, el andaluz hablado representa una fase más evolutiva que el español peninsular pero menos que el español de América: la perífrasis se emplea ligeramente más que en Las Palmas y Madrid pero algo menos que en gran parte de América (salvo en México):

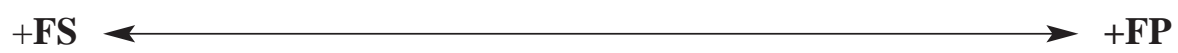

\section{español "normativo" > canario > andaluz > español de América}

\section{Conclusión}

En síntesis, en este breve estudio comparativo hemos tenido ocasión de comprobar que la copla flamenca como proceso comunicativo no adopta, en el uso de las formas estudiadas, el mismo código lingüístico que el andaluz hablado: mientras que éste prefiere el FP (64\%), aquél recurre mucho más a menudo a la forma en - ré $(86 \%)$.

A pesar de esta distribución global superpuesta, los usos semántico-sintácticos de ambas formas son bastante similares en flamenco y en andaluz hablado. El cuadro siguiente recoge algunos factores explicativos que inciden favorablemente en el uso del FP o FS en ambas variedades: 


\section{Cuadro 9}

\begin{tabular}{|c|c|c|}
\hline & Forma en -ré & $\langle$ ir $a+$ infinitivo $>$ \\
\hline TEMPORAL & $\begin{array}{l}\text { - con indicadores temporales de } \\
\text { distancia máxima } \\
\text { - en la } 3^{\mathrm{a}} \text { persona } \\
\text { - expresa sobre todo alejamiento }\end{array}$ & $\begin{array}{l}\text { - en las independientes y contextos } \\
\text { de dependencia sintáctica (p.e. la } \\
\text { prótasis de las condicionales, las } \\
\text { subordinadas temporales) } \\
\text { - con indicadores temporales de } \\
\text { inmediatez y proximidad } \\
\text { - en la } 1^{\text {a }} \text { persona } \\
\text { - expresa cada grado de distancia } \\
\text { temporal }\end{array}$ \\
\hline MODAL & $\begin{array}{l}\text { - prevalece en la mayoría de los } \\
\text { contextos sintácticos } \\
\text { - con indicadores modales verbales } \\
\text { - en la } 3^{\text {a persona }} \\
\text { - modalidad epistémica (futuro de } \\
\text { probabilidad) }\end{array}$ & $\begin{array}{l}\text { - en las oraciones independientes } \\
\text { - la entonación (p.e. las interrogativas) } \\
\text { - este uso se limita al andaluz } \\
\text { hablado } \\
\text { - en la } 1^{\text {a }} \text { persona } \\
\text { - modalidad intencional } \\
\text { - modalidad epistémica } \\
\text { - se limita al andaluz hablado y en } \\
\text { combinación con indicadores } \\
\text { modales }\end{array}$ \\
\hline
\end{tabular}

Aunque este supuesto sistema de preferencias de la forma en -ré e <ir $a+$ infinitivo> coincide más o menos en flamenco y en andaluz hablado, insistimos en que no existen condicionantes precisos ni exigencias unívocas del sistema. Además, las diferencias señaladas entre ambos códigos lingüísticos no conciernen tanto al uso concreto del FP y FS sino que destacan más bien algunas divergencias estadísticas ${ }^{31}$ importantes: en general, los datos van en el mismo sentido, a saber una progresiva extensión de la perífrasis. Expresando cada grado de distancia temporal, <ir $a+$ infinitivo> no sólo extiende sus usos temporales en detrimento del FS (tendencia presente en flamenco y en andaluz hablado) sino que

31. Veáse los cuadros 2 hasta 5. 
adopta además los mismos valores modales de la forma en -ré (tendencia únicamente presente en andaluz hablado y en combinación con algún indicador). El estudio de los factores sintácticos confirma el proceso de avance de la perífrasis en el sentido de que ésta se utiliza indiferentemente en todos los contextos $\underline{\sin }-$ tácticos (tendencia más presente en andaluz hablado y exclusivamente en los casos de dependencia sintáctica).

En fin, los datos obtenidos confirman cierta evolución en el sistema verbal, por lo menos en andaluz hablado en que la perífrasis ha desplazado en mayor medida a la forma sintética. Sin embargo, en la fase actual de la evolución, esta reestructuración y supuesta "decadencia" del FS sólo afecta al sistema temporal de futuridad: tanto en el habla andaluza como en flamenco, la perífrasis expresa cada vez más una temporalidad lejana. En el campo de la modalidad en cambio, no nos atreveríamos a defender una reorganización total de los valores: en su uso modal -y particularmente indicando una relación de simultaneidad-, la forma en -ré tiene gran productividad, incluso en la lengua hablada. Además, la modalidad epistémica expresada por <ir $a+$ infinitivo> se limita a algunos casos concretos en que la forma está determinada por algún indicador modal. En este sentido, la forma en -ré no está condenada a una desaparición inminente y absoluta del paradigma verbal: sigue manteniendo una productividad considerable en la lengua escrita, en el nivel culto y en el campo de la modalidad.

\section{Bibliografía}

Alonso, Amado y Henríquez Ureña, Pedro, Gramática castellana. Madrid, Arco/ Libros, 1935.

Bauhr, Gerhard, El futuro en -ré e ir a + infinitivo. El español peninsular moderno. Göteborg, Acta Universitatis Gothoburgensis, 1989.

Bello, Andrés, Gramática de la lengua castellana destinada al uso de los americanos. Madrid, Arco/Libros, 1988.

Berschin, Helmut, "Futuro analítico y futuro sintético en el español peninsular y colombiano", en: Lingüística española actual IX, 1. Madrid, Arco/Libros, 1987, pp 101-110.

Bosque, Ignacio y Demonte, Violeta, Gramática descriptiva de la lengua española. Madrid, Espasa-Calpe, 1999.

Cartagena, Nelson, "Estructura y función de los tiempos del modo indicativo en el sistema verbal del español”, en: Revista de lingüística teórica y aplicada 14-15, 1976-1977, pp 5-44. 
Cartagena, Nelson, "Sistema, norma y habla del futuro de probabilidad español", en: Logos semantikos: studia lingüistica in honorem Eugenio Coseriu, vol IV. Madrid, Gredos, 1981, pp 383-393.

Coseriu, Eugenio, "Sobre el futuro romance", en: Estudios de lingüística románica. Madrid, Gredos, 1977, pp 15-39.

Fleishmann, Suzanne, The Future in Thought and Language. Diachronic Evidence from Romance. Cambridge, Cambridge University Press, 1982.

Gómez Manzano, Pilar, "La expresión del futuro absoluto en el español hablado en Madrid y en México", en: Anuario de Letras 26, 1988, pp 67-86.

Kitova-Vasileva, Maria, La verosimilitud relativa y su expresión en español. Santiago de Compostela, Universidad de Santiago de Compostela, 2000.

Lorenzo, Emilio, "Notas sobre el verbo español", en: El español de hoy, lengua en ebulliciòn. Madrid, Gredos, 1980, pp 97-113.

Meier, Harri, "Futuro y futuridad", en: Revista de Filología española, Anejo 48. Madrid, Graficas Condor, 1965, pp 61-77.

Montes G., José Joaquín, "Sobre la categoría de futuro en el español de Colombia", en: Thesaurus: Boletín del instituto Caro y Cuervo 18, 1962, pp 527-555.

Montes G., José Joaquín, "Sobre las perífrasis con "ir" en el español de Colombia", en: Thesaurus: Boletín del instituto Caro y Cuervo 18, 1963, pp 384-403.

Moreno de Alba, José, "Vitalidad del futuro de indicativo en la norma culta del español hablado en México", en: Anuario de Letras 8, 1970, pp 81-102.

Rodríguez Díez, Bonifacio, Las lenguas especiales: el léxico del ciclismo. León, Colegio universitario de León, 1981.

Rojo, Guillermo, "La temporalidad verbal en español", en: Verba 1. Santiago de Compostela, Universidad de Santiago de Compostela, 1974, pp 68-149.

Rojo, Guillermo, "Temporalidad y aspecto en el verbo español”, en: Lingüística española actual 10, 2. Madrid, Arco/Libros, 1988, pp 195-216.

Ropero Núñez, Miguel, "Aspectos gramaticales en el lenguaje especial del cante flamenco", en: Méndez E., Mendora J. y Congosto Y., Indagaciones sobre la lengua, Estudios de Filología y lingüística en memoria de Emilio Alarcos. Sevilla, Universidad de Sevilla, 2001, pp 455-470.

Sáez Godoy, Leopoldo, "Algunas observaciones sobre la expresión del futuro en español”, en: Actas del XI Congreso Internacional de Lingüística y Filología Románicas, vol. IV, Madrid, CSIC, 1986, pp 1875-1890.

Seco Reymundo, Manuel, Gramática esencial del español. Introducción al estudio de la lengua. Madrid, Aguilar, 1989.

Sedano, Mercedes, "El futuro morfológico y la expresión ir a + infinitivo en el español hablado de Venezuela", en: Verba 21. Santiago de Compostela, Universidad de Santiago de Compostela, 1994, pp 225-240. 
Troya Déniz, Magnolia, Perífrasis de infinitivo en la norma lingüística culta de las Palmas de Gran Canaria. Madrid, Real Academia Española, 1998.

Veiga, Alexandre, "El presente histórico como hecho de sistema verbal", en: Verba 14. Santiago de Compostela, Universidad de Santiago de Compostela, 1987, pp 169-216.

Veyrat Rigat, Monserrat, "Aspecto, perífrasis y auxiliación: un enfoque perceptivo", en: Lynx, Annexa 6. Valencia, Universidad de Valencia, 1993, pp 9-214.

Wilmet, Marc, Grammaire critique du français. Paris, Duculot, 1997.

\section{Corpus:}

Lamíquiz, Vidal, "Encuestas del habla urbana de Sevilla. Nivel culto", en: Pineda Pérez, Miguel Ángel, Sociolingüística andaluza 2. Sevilla, Universidad de Sevilla, 1983.

Lamíquiz, Vidal, "Encuestas del habla urbana de Sevilla. Nivel popular", en: Ropero Núñez, Miguel, Sociolingüística andaluza 4. Sevilla, Universidad de Sevilla, 1987.

Machado y Álvarez, Antonio, "Demófilo", Cantes flamencos, recogidos y anotados por Antonio Machado y Álvarez (Demófilo). Madrid, Cultura Hispánica, 1975 (1881).

Machado y Álvarez, Antonio, Cantes flamencos y cantares. Madrid, EspasaCalpe, 1998 (1881).

Moreno Galvan, Francisco, Letras flamencas. Madrid, Universidad Autónoma de Madrid, 1993.

Rodríguez Marín, Francisco, Cantos populares españoles, vol. I, II, III. Sevilla, Francisco Álvarez et alii (eds.), 1882-1883. 